\title{
Effectiveness of a comprehensive sexual and gender-based violence prevention project for in-school girls in Swaziland
}

Swaziland Action Group Against Abuse (SWAGAA)

Follow this and additional works at: https://knowledgecommons.popcouncil.org/departments_sbsr-rh

Part of the Domestic and Intimate Partner Violence Commons, Educational Sociology Commons, International Public Health Commons, Maternal and Child Health Commons, and the Women's Health Commons How does access to this work benefit you? Let us know!

\section{Recommended Citation}

Swaziland Action Group Against Abuse (SWAGAA). 2013. "Effectiveness of a comprehensive sexual and gender-based violence prevention project for in-school girls in Swaziland." Manzini, Swaziland: SWAGAA. 
EFFECTIVENESS OF A COMPREHENSIVE SEXUAL AND GENDER-BASED VIOLENCE PREVENTION PROJECT FOR IN-SCHOOL GIRLS IN SWAZILAND

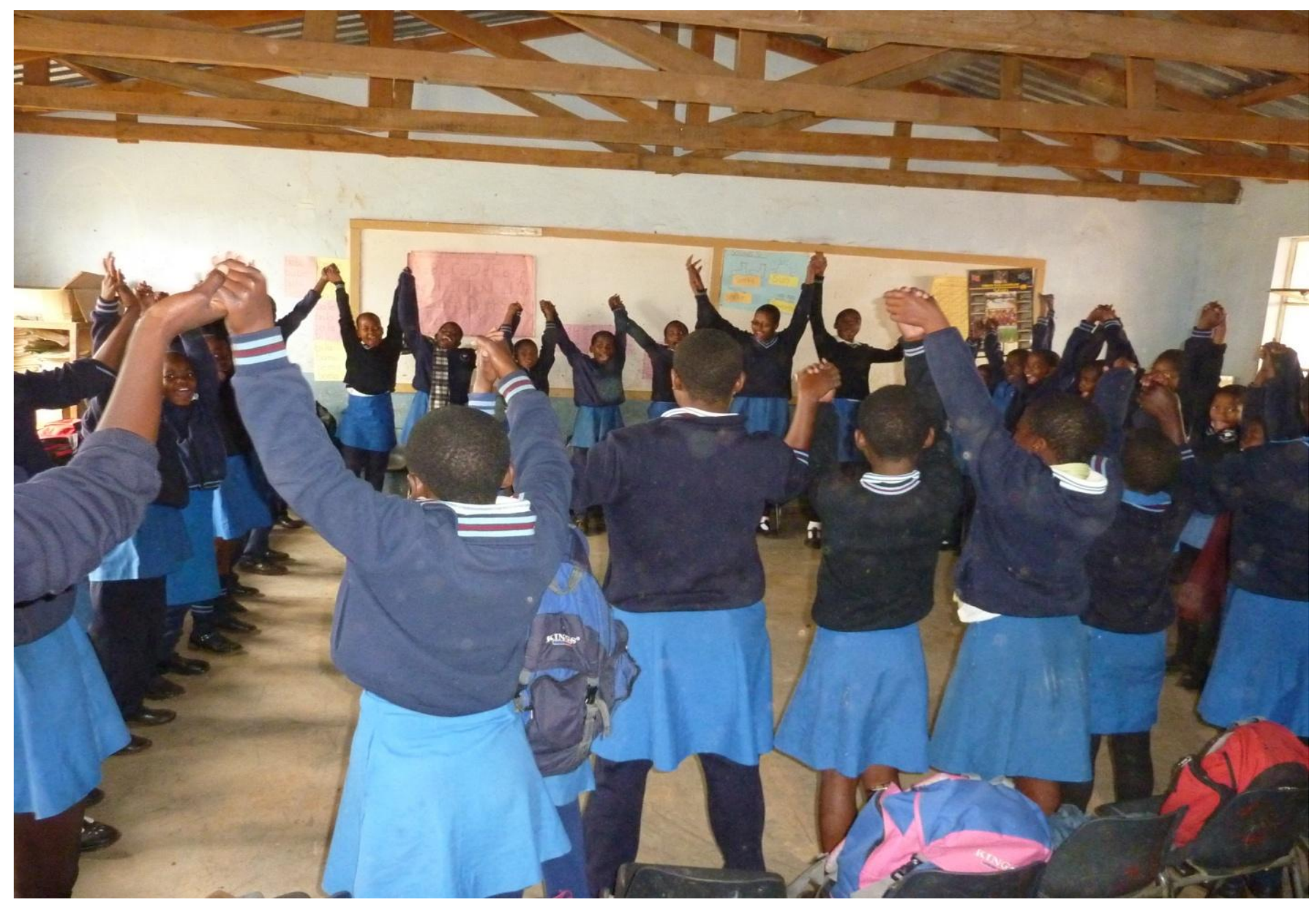




\section{Effectiveness of a comprehensive sexual and gender-based violence prevention project for in-school girls in Swaziland}

Suggested Citation: Swaziland Action Group Against Abuse (SWAGAA). 2013. Effectiveness of a comprehensive sexual and gender-based violence prevention project for in-school girls in Swaziland. SWAGAA: Manzini, Swaziland.

December 2, 2013

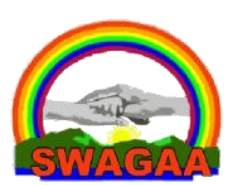


The implementation of the research based project would not have been possible without the support, partnership and collaboration with key national and international stakeholders. Accordingly, the SWAGAA Team would like to acknowledge the following partners and stakeholders:

- Population Council Zambia, particularly Dr Jill Keesbury (formerly the Country Director of the Zambia Office) and Population Council Kenya, for the invaluable technical support and guidance throughout the duration of the project; in particular, special gratitude is extended to Dr Chi-Chi Undie and Dr Francis Onyango.

- the Africa Regional Sexual and Gender-Based Violence Network from which the initiative was adapted;

- the Ministry of Education, the Regional Education Officer in the Lubombo region who helped us select the intervention schools (Malindza, Lusoti and Ngomane High Schools);

- the School Authorities who allowed us access to their schools;

- the parents who gave us permission to engage their children;

- the Royal Swaziland Police for their assistance and contribution towards the study and also attending to the girls with urgency;

- the Malindza and RSSC Community in Simunye for being supportive towards this program and providing assistance to the organisation and students;

- the Teachers in all the three schools, who were of great assistance in establishing the clubs and maintaining their existence;

- the Mentors who worked hand in hand with the teachers in the schools. They made our work easy, by doing their part throughout the program;

- the SWAGAA Counsellors, who always availed themselves to assist the girls whenever they needed someone to confide in;

- $\quad$ and the Students whom we are hoping this program will benefit the most, for participating in the study, being active in the clubs and providing honest, open feedback while also sharing their experiences. 


\section{TABLE OF CONTENTS}

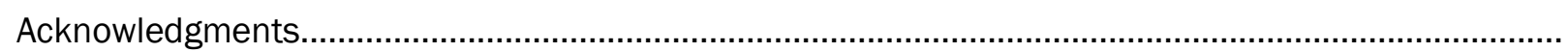

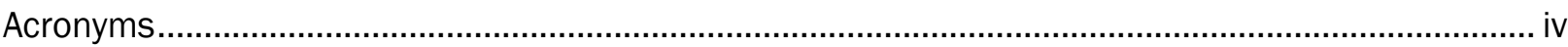

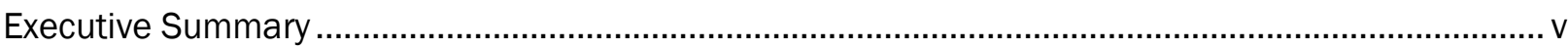

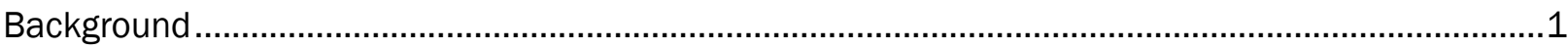

Addressing SGBV in Swaziland: GEC-PLUS Project .........................................................................

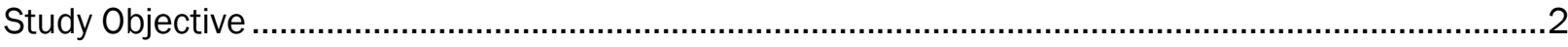

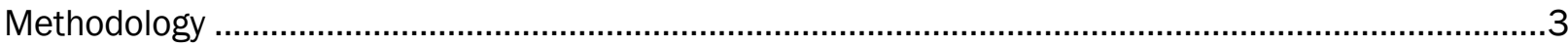

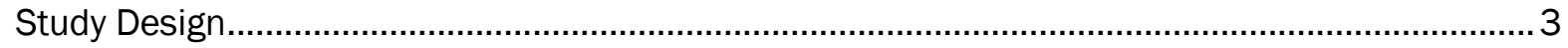

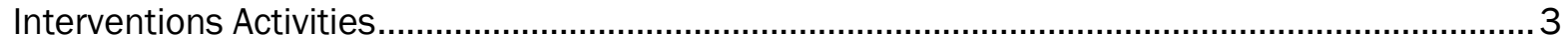

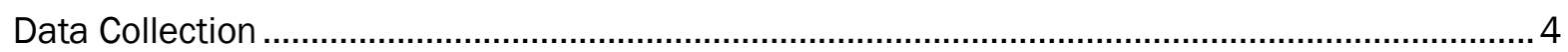

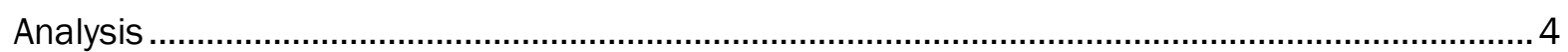

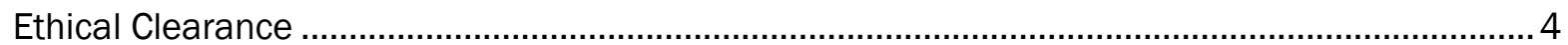

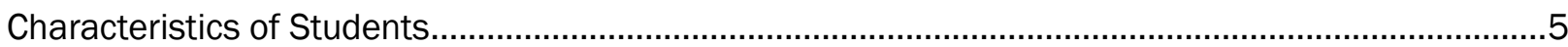

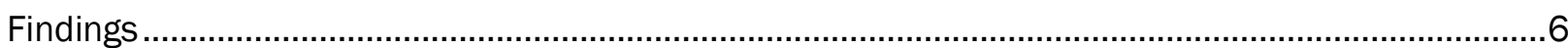

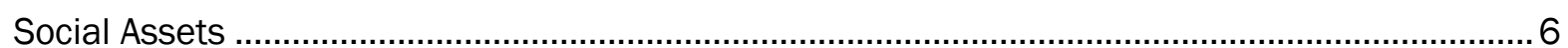

Awareness about Sexual and Gender-based Violence ............................................................... 6

Practices and Experiences Related to Sexual and Gender-based Violence..................................... 8

Attitudes towards Sexual and Gender-based Violence................................................................10

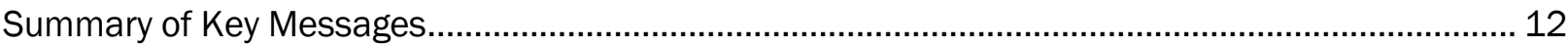

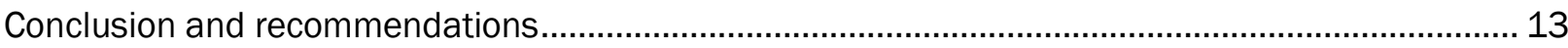

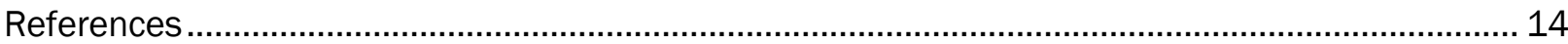




\section{LIST OF TABLES}

Table 1: Percent distribution of students by background characteristics and study round .5

Table 2: Distribution of students by indicators of social assets, study site and round.........................6

Table 3: Distribution of students by awareness about sexual and gender-based violence at

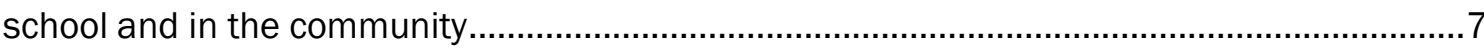

Table 4: Distribution of students by sexual and gender-based violence practices ..............................9

Table 5: Distribution of students by experiences of sexual and gender-based violence at

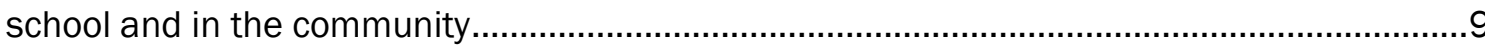

Table 6: Distribution of students by attitudes towards sexual and gender-based violence

\section{LIST OF FIGURES}

Figure 1: Distribution of students by reported forms of sexual violence against girls at school at baseline and endline.

Figure 2: Distribution of students by reported forms of sexual violence against girls in the community at baseline and endline

Figure 3: Distribution of students by reported perpetrators of sexual and gender-based violence in the community for combined baseline and endline 


\section{ACRONYMS}

AIDS

CSO

FGD

GEC

GEP

HIV

NGO

SADC

SGBV

$\mathrm{SRH}$

SWAGAA
Acquired Immune Deficiency Syndrome

Central Statistics Office

Focus Group Discussion

Girls' Empowerment Clubs

Girls' Empowerment Program

Human Immunodeficiency Virus

Non-Governmental Organization

Southern African Development Community

Sexual and Gender-Based Violence

Sexual and Reproductive Health

Swaziland Action Group Against Abuse 


\section{EXECUTIVE SUMMARY}

Swaziland is one of the sub-Saharan African countries affected by Sexual and Gender Based Violence (SGBV) and HIV and AIDS, with women facing greater risk compared to men. In response to increasing reports of violence against women and children in the country, the Swaziland Action Group Against Abuse (SWAGAA) launched a Girls' Empowerment Clubs (GEC) program in primary and secondary schools in order prevent SGBV cases. Due to limitations of the program (such as being led by teachers and reliance on volunteers), an intervention study was carried out from 2012 to 2013 to test the effectiveness of an enhanced version, 'GEC-Plus,' that used a 'Safe Spaces' approach of building the girls' social assets in order to mitigate SGBV. The overall goal of the project was to prevent SGBV and improve reporting of SGBV cases among in-school girls. The specific objective of the study was to assess the effectiveness of implementing the GEC-Plus project on SGBV knowledge, attitudes, and practices among in-school girls in Swaziland.

The study used a pre- and post-intervention design without a comparison group and included three girls' secondary schools in the Lubombo Region in Eastern Swaziland which were selected in collaboration with the Ministry of Education Regional Office. Data collection involved baseline and endline quantitative interviews with in-school girls ages 16 and above who participated in the GECPlus program. This report summarizes the key results emerging from the study.

\section{Key Findings}

- The proportion of students that reported ever experiencing any form of sexual and gender-based violence either at school or in the community significantly increased from $50 \%$ at baseline to $67 \%$ at endline.

- There were significant improvements in the social assets of girls, especially with respect to engaging in an income-generating activity, having many friends in the neighbourhood, having two or more close friends that they could confide in, and taking part in extra-curricular activities.

- There was a significant improvement in awareness about girls being teased or subjected to verbal sexual harassment. There was also significant increase in the proportion of girls reporting being subjected to sexual comments by fellow students at their institutions.

- There were significant improvements in the proportion of girls that indicated that they would report incidents of sexual harassment by a student to teachers, school principal or the police. There was, however, no significant change in the proportion of students that would report similar incidents by a teacher.

- The interventions did not have any effect on the possibility that students would decline sexual advances from a student or teacher. In particular, there were non-significant changes in the proportion of students that reported that they would say no or not agree to a request by another student or teacher to have sex.

- There were significant positive changes in the attitudes of students from intervention schools regarding sexual and gender-based violence in 13 out of 21 items used to measure attitudes towards SGBV. 


\section{Conclusion}

The study findings show very high levels of reported abuse among in-school girls in Swaziland. The GEC-Plus interventions were effective in improving girls' social assets, increasing their awareness, and positively changing their attitudes towards SGBV. The interventions were, however, less successful in changing the possibility that the students would decline sexual advances from fellow students or teachers.

\section{Recommendations}

The primary recommendations from the study are as follows:

1. Strengthen the GEC-Plus model by incorporating components aimed at enhancing selfefficacy among girls. This could help increase the likelihood of girls declining unwanted sexual advances by teachers and fellow students.

2. Foster wider community linkages with the GEC-Plus program to help address SGBV outside the school context (which girls referred to), to ensure sustainability of the program, and to extend the reach of the program to other populations.

3. Diversify GEC-Plus activities for the girls, while maintaining a key focus on SGBV.

4. Engagement by SWAGAA and key stakeholders in extensive advocacy and lobbying to facilitate the institutionalization of the GEC-Plus program into Government of Swaziland structures through the Ministry of Education. 
Sexual and gender based violence (SGBV) is a global health and human rights problem with immediate and long-term health and social impacts. SGBV is of particular concern in sub-Saharan Africa because of the compounding effects of high HIV prevalence. For example, in Swaziland - a small, land-locked country of just over one million people - women face the disproportionate burden of both SGBV and HIV. A 2007 population-based national survey on violence against young women aged 13-24 years found that approximately $40 \%$ of them reported lifetime experience of physical or sexual violence, while among girls in secondary school (aged 13-17 years), 13\% reported that their first sexual experience was coerced (Reza et al. 2007). In addition, 48\% of those aged 13-24 years reported having experienced some form of sexual violence (rape, threat of rape, unwanted touching or groping), most often by a boyfriend or husband while $25 \%$ had experienced physical violence, typically by a male relative ( ibid.). Among those aged $13-17$ years, only $37 \%$ reported that their first sexual experience was voluntary, while the rest said it was through persuasion (39\%), trickery/deception (13\%), or rape (10\%). Estimates from the 2006-2007 Swaziland Demographic and Health Survey further show a 31\% lifetime prevalence of SGBV among women aged 15-49 and 20\% among men (Central Statistics Office [CSO] and Macro International Inc. 2008).

Although available evidence suggests that most SGBV cases occur in the home or community, schools are not entirely safe places for girls. For example, findings from a national survey on violence against children in Swaziland (Reza et al. 2007) indicate that among incidents of sexual violence experienced before age 18 in Swaziland, 10\% occurred at school and another 10\% on the way to and from school. In addition, $2 \%$ of incidents of sexual violence before age 18 were perpetrated by a teacher. However, the reporting of SGBV cases remains low. For instance, less than half $(48 \%)$ of girls who had experienced sexual violence before age 18 told someone about it, while only 1 in 7 actually sought legal, health, or social services. The primary reason for not getting help was that most did not realize that what occurred was sexual violence, indicating a clear need for greater awareness raising and empowerment among young women and girls in Swaziland.

There is growing evidence of direct and indirect links between SGBV and HIV, with violence being both a cause and outcome of HIV infection (Jewkes et al. 2009; Reza et al. 2009). The national HIV prevalence among adults (15-49) in Swaziland is 26\% - one of the highest in the world (CSO and Macro International Inc. 2008). Factors driving SGBV include cultural norms and values that legitimize unequal power relations between men and women, stigma and silence around reporting violence, high poverty levels, increasing numbers of HIV-related orphaned and vulnerable children (estimated 70,000 in 2008) and reduced family and social resources due to health and natural disasters; (CSO and Macro International Inc. 2008). While systematic data collection on SGBV is limited, especially in certain groups (e.g. men and boys), the Swaziland Action Group Against Abuse (SWAGAA) - the leading SGBV response organization in country - reports increases in violence, particularly among children (SWAGAA 2011).

The Swazi government has acknowledged the importance of promoting gender equity and preventing violence against women and girls in its national plans and policies. Part of Swaziland's 2003 National Population Policy calls for promoting gender equity and equality at all levels of society and reducing the social and economic impact of HIV and AIDS. The National Gender Policy (2010), guided by international and regional instruments, has the stated goal of strengthening national efforts in providing equal opportunities for women and men, girls and boys, to attain gender equality, social justice, and economic efficiency, and includes addressing SGBV and human rights as key thematic areas (GOS 2010). The Swazi government also has ratified several international binding human rights documents, including the Convention on the Elimination of All forms of Discrimination Against Women (ratified in 2004); the Southern African Development Community (SADC) Maseru Declaration (2003) to promote Gender and Development, with an explicit mandate to promote women's and girls' empowerment, and the Convention on the Rights of the Child (1995). Whereas these commitments promote a favourable policy environment to combat SGBV, their implementation has been slow. 
Effective responses to SGBV in Swaziland require multi-sectoral, locally-adapted, age- and genderappropriate strategies that emphasize prevention. SWAGAA is, for example, a non-governmental organization that was founded in 1990 in response to increasing reports of violence against women and children in the country. Based on the findings of the 2007 national survey on SGBV that revealed the staggering rates of violence against women and girls (Reza et al. 2007), SWAGAA launched a girls empowerment clubs (GEC) program in eight primary (ages 9-13) and secondary (ages 14-17) schools around the country, with a total of 250 girls by 2011. An unpublished, preliminary evaluation of the GEC program suggested that participants were both interested in and committed to it, with demonstrable increases in their knowledge on the core topics. However, the program faced various challenges. For example, the teacher-led structure and limited resources did not allow all interested girls in each school to participate. Of the 350 to 400 girls in each school, only 40 to 60 could join the groups. In addition, reliance on a few dedicated volunteer teachers to oversee the clubs posed problems for program continuity when teachers left or transferred to other schools. Some teachers also complained that running the clubs took too much time and responsibility. There was also a possibility that girls might feel more comfortable working with peers or mentors from outside the school than their teachers.

To overcome some of these challenges, SWAGAA, in collaboration with the Population Council, implemented an enhanced GEC project ('Girls Empowerment Clubs Plus' or 'GEC-Plus') based on the Council's 'Safe Spaces' approach (Baldwin 2011). The Safe Spaces approach was pioneered by the Population Council in Africa and Latin America in order to address the social determinants of vulnerability to HIV, early marriage, and sexual violence by building girls' social, economic, and leadership "assets" (Austrian and Ghati 2010). The core elements of the approach are a safe place for vulnerable girls, friendship structures, and mentors. The approach involves a cascading leadership model whereby older girls from the community are recruited and trained to be mentors to the girls' groups. Girls who graduate from the program have the opportunity to be trained as mentors for the next group; they therefore have access to mentors as well as develop and practice leadership skills (Austrian and Ghati 2010). Evidence from several countries show that these programs help delay marriage and (often forced) sexual initiation, keep girls in school, and help promote an array of heath behaviours such as safe sex and nutrition (Brady et al. 2007; Erulkar et al. 2008; Erulkar et al. 2009; Catino et al. 2009).

The overall goal of the project was to prevent SGBV and improve reporting of SGBV cases among inschool girls by using the Safe Spaces approach of building the girls' social assets in the Swazi context. The project focused on the friendship and mentoring elements of the Safe Spaces approach, including: 1) shifting from a didactic/knowledge-acquisition model of learning to one that builds girls' social assets, specifically leadership skills and social networks; 2) educating and empowering girls with SGBV information, and emphasizing the need to report cases of SGBV in their schools and communities; 3) using a mentor-driven rather than a teacher-led approach, engaging older girls from surrounding communities; and 4) strengthening the monitoring and evaluation of the program.

\section{STUDY OBJECTIVE}

The specific objective of this study was to assess the effectiveness of implementing the GECPlus project on SGBV knowledge, attitudes, and practices among in-school girls. 


\section{Study Design}

The study used a pre- and post-intervention design without a comparison group. Three secondary schools in Lubombo, a rural region in Eastern Swaziland, were selected for inclusion in the study in collaboration with the Regional Ministry of Education on the following basis:

- They did not have a girls' club at the time of the project;

- They served more vulnerable populations as determined by reported cases of SGBV and other social and health indicators from the 2006-2007 Swaziland Demographic and Health Survey, National Survivor Abuse database, and SWAGAA reports;

- They had previously expressed interest in piloting a girls' club; and

- They were located within communities with populations sizeable enough to allow for recruiting at least 10 mentors.

\section{Interventions Activities}

The interventions were implemented over a period of twenty nine months from July 2012 to December 2013 and involved the following major activities:

- Revision of training curriculum and manuals;

- Sensitization of school authorities and students

- Selection and training of mentors;

- Recruitment of GEC-Plus participants (including eliciting consent;

- Conducting baseline data; and

- Conducting GEC-Plus sessions.

Revision of training curriculum and manuals: SWAGAA's existing GEC curriculum, teacher/girl manuals, and reporting forms were revised to incorporate the friendship and mentoring elements of the Safe Spaces approach. The manuals addressed SGBV as the main focus; providing comprehensive information on Gender, defining SGBV, providing examples and explanations of the forms of SGBV, providing information on how to identify a risky situation and prevent violence and how to report violations; among other key issues. A meeting was then held with a small group of local stakeholders, including the Regional Education Officer, head and guidance teachers from the project sites, and community representatives to introduce the project and elicit their views on the proposed project.

Selection and training of mentors: Fifteen (15) young women aged 18-25 years were recruited from the same communities where most GEC-Plus girls live for training as mentors (five mentors for each school or one per group of 20 girls). The mentors were trained over a period of three days on the GEC-Plus curriculum and their roles and responsibilities as mentors during the project. The training focused on the Safe Spaces approach, the GEC-Plus project, an introduction to SGBV, recruiting girls for the clubs, the roles of mentors, SGBV reporting in schools (through mentors) and referrals, and SWAGAA programs and resources. Mentors were responsible for running the GEC-Plus. They reported directly to SWAGAA and were compensated for their time based on local rates for equivalent work. The guidance teachers at the participating schools played a secondary role consisting of attending stakeholder meetings; securing a "safe space" (two classrooms) on school premises for the GEC-Plus clubs to hold meetings; and facilitating communication between SWAGAA, the mentors, and the school administrators.

Recruitment of GEC-Plus participants: A SWAGAA Project Coordinator made an initial site visit to the schools to introduce the project and outline the roles of and expectations for all participants. In each school site, all girls aged 16 to 18 years (with older girls as exceptions) were asked to consider participating in the project after being informed of the expectations for participation. The project targeted 100 girls in each school from Form 1 to Form 5. The guidance teachers assisted with recruiting girls into the program. Girls who were willing to participate in the project were given consent forms to take home to their parents/guardians to sign. The forms served as informed 
consent both for participating in the GEC-Plus program and for taking part in the baseline and endline interviews. The first 100 girls that returned completed parent/guardian consent forms were then invited to join the clubs after completing their own student assent forms. The remaining students were put on a waiting list to replace those who might drop out during the sessions in order to maintain about 100 participants. The guidance teachers assisted with issuing periodic reminders to the girls to encourage them to complete the consent forms.

Conducting GEC-Plus sessions: A normal session would take place in the safe space (in this, case, a class room) with the participation of the girls and their mentor. Activities would include different topics to be discussed that could come from the manual or from the girls (HIV and AIDS, child abuse, sexual abuse and rape, health education, public speaking, economic empowerment, etc.). Sessions were held once a week with the average number of girls per club being 20 .

\section{Data Collection}

Data collection involved quantitative interviews. The baseline data were collected in October 2012, while the endline interviews took place from October to November 2013.

All girls participating in the GEC-Plus project (100 in each school) were targeted for quantitative interviews at baseline and endline. However, a total of 247 students participated in the baseline interviews while 143 students participated in the endline interviews. The interviews involved the use of anonymous self-administered questionnaires to allow for anonymity (Mitchell and Jolly 2010) among in-school girls within school contexts where authority figures cannot be ruled out as perpetrators of SGBV. Furthermore, anonymous self-administered questionnaires are thought to be more effective for examining sensitive issues (such as SGBV), and can make respondents feel more comfortable about reporting behaviour related to these issues (Babbie 2011).

The interviews were conducted as a class exercise and took about one hour. Girls were given copies of the questionnaire to complete on their own at their desks. A trained field worker read aloud each question and the girls marked their responses. Before completing the questionnaire, the participants were informed that they should not write their names or registration numbers on the forms and that they could stop at any time or skip any questions they did not want to answer.

Information was collected on participants' socio-demographic characteristics (such as age, grade, parental composition [mother-father compared with mother-only or father-only families], and living arrangements); involvement in income-generating and extra curricula activities; involvement with friends; perceptions about the prevalence of SGBV at school and in the community; experiences with SGBV in both settings (school and community); as well as attitudes towards SGBV. At the end of the interviews (before anyone left the room), the study team informed the girls about resources for SGBV, especially SWAGAA services and how to seek help at the nearest office.

\section{Analysis}

The quantitative data from self-administered interviews were entered in Excel and analyzed using STATA and Excel. Analysis entailed simple frequencies, percentages and cross-tabulations with Chisquare tests as well as significance tests of proportions, and a comparison of baseline and endline results.

\section{Ethical Clearance}

The study obtained ethical approval from the Population Council Institutional Review Board and the Swaziland Ethics and Research Committee. 


\section{CHARACTERISTICS OF STUDENTS}

Table 1 presents the distribution of students who participated in the baseline and endline interviews by background characteristics. At both baseline and endline, the majority of students were aged 1618 years ( $46 \%$ at baseline and $83 \%$ at endline), were in Form 4 (38\% at both baseline and endline), had both parents alive (63\% at baseline and $62 \%$ at endline), had no sexual partner (61\% at baseline and $57 \%$ at endline), lived in households with between 5 and 9 members (53\% at baseline and $57 \%$ at endline), and came from households where the father was mostly responsible for their upbringing (49\% at baseline and 53\% at endline). There were, however, significant differences between in the distribution of students by age and grade between baseline and endline $(p<0.01$ in each case; Table 1). In addition, there were significant differences in the distribution of students by current relationship status and household wealth quintile between baseline and endline $(p<0.05$ in each case; Table 1). Nonetheless, the distribution of students did not significantly differ between baseline and endline with respect to parental composition, number of household members, and the person who was mostly responsible for their upbringing.

Table 1: Percent distribution of students by background characteristics and study round

\begin{tabular}{|l|l|l|}
\hline Characteristics & $\begin{array}{l}\text { Baseline (\%) } \\
(\mathrm{N}=247)\end{array}$ & $\begin{array}{l}\text { Endline (\%) } \\
(\mathrm{N}=143)\end{array}$ \\
\hline Age group & $\mathrm{p}<0.01$ & \\
<16 years & 11.7 & 0.0 \\
16-18 years & 45.8 & 82.5 \\
19 years and above & 14.6 & 16.1 \\
Missing & 27.9 & 1.4 \\
\hline Grade & $\mathrm{p}<0.01$ & \\
Form 1 & 7.3 & 7.7 \\
Form 2 & 8.5 & 14.7 \\
Form 3 & 16.2 & 12.6 \\
Form 4 & 38.1 & 37.8 \\
Form 5 & 17.0 & 27.3 \\
Missing & 13.0 & 0.0 \\
\hline Parental composition & $\mathrm{p}=0.67$ & \\
Both parents & 62.8 & 61.5 \\
One parent & 30.4 & 30.8 \\
No parents & 6.1 & 7.7 \\
Don't know/missing & 0.8 & 0.0 \\
\hline Current relationship status & $\mathrm{p}<0.05$ & \\
Has steady partner & 21.9 & 30.1 \\
Has non-steady partner & 11.3 & 11.9 \\
Has no partner & 61.1 & 57.3 \\
Missing & 5.7 & 0.7 \\
\hline Number of household members & $\mathrm{p}=0.07$ & \\
1-4 & 31.2 & 35.0 \\
5-9 & 53.4 & 56.6 \\
10 and above & 11.3 & 8.4 \\
Missing & 4.1 & 0.0 \\
\hline Household wealth index & $p<0.05$ & \\
Poorest quintile & 18.2 & 22.4 \\
Poorer quintile & 21.1 & 18.2 \\
Middle quintile & 19.0 & 21.7 \\
Richer quintile & 16.6 & 25.9 \\
Richest quintile & 25.1 & 11.9 \\
\hline Person mostly providing support & $\mathrm{p}=0.48$ & \\
Mother & 32.0 & 25.2 \\
Father & 49.4 & 52.5 \\
Grandparent & 4.1 & 9.8 \\
Sibling & 7.7 & 7.7 \\
Other & 5.7 & 0.0 \\
Missing & 1.2 & \\
\hline Notes: Percentages may not sum to exactly 100 due & rounding; p-values are from Chi-square tests of differences \\
\multicolumn{1}{|c|}{ between baseline and endline. } & & \\
\hline
\end{tabular}




\section{FINDINGS}

The effectiveness of the GEC-Plus interventions is examined in terms of changes between baseline and endline in students':

1) Social assets;

2) Awareness about SGBV;

3) Practices and experiences related to SGBV; and

4) Attitudes towards SGBV.

\section{Social Assets}

Social assets were measured by whether the students were engaged in any income-generating activity, had many friends in the community, had two or more close friends with whom they could share personal secrets or concerns, had someone they could turn to when faced with difficulty, and were involved in any extra curricula activities at school such as sports and clubs. The results are presented in Table 2. There was a significant increase between baseline and endline in the proportion of students that reported that they were engaged in an income-generating activity (from $6 \%$ and $13 \% ; p<0.05)$. Similarly, the proportion of students that reported that they had many friends in the community significantly increased from $41 \%$ at baseline to $52 \%$ at endline $(p<0.5)$, while the proportion that reported having two or more close friends they could share personal secrets or concerns with significantly increased from $60 \%$ at baseline to $74 \%$ at endline $(p<0.01)$. In addition, the proportion of students that reported taking part in any extracurricular activities significantly increased from $68 \%$ at baseline to $100 \%$ at endline.

Table 2: Distribution of students by indicators of social assets, study site and round

\begin{tabular}{|l|l|l|}
\hline Indicators of social assets & $\begin{array}{l}\text { Baseline (\%) } \\
\mathbf{( N = 2 4 7 )}\end{array}$ & $\begin{array}{l}\text { Endline (\%) } \\
(\mathbf{N}=\mathbf{1 4 3})\end{array}$ \\
\hline Doing any activity that earns money for self or family & 6.1 & $12.6^{*}$ \\
\hline Has many friends in the neighbourhood & 41.3 & $51.8^{*}$ \\
\hline Has two or more close friends to share secrets & 59.9 & $73.8^{* *}$ \\
\hline Has someone to turn to when faced with difficulty & 82.2 & 88.1 \\
\hline Takes part in any extra curricula activities & 68.0 & $100.0^{* *}$ \\
\hline
\end{tabular}

Notes: ${ }^{*} p<0.05 ;{ }^{* *} p<0.01$.

\section{Awareness about Sexual and Gender-based Violence}

Results in Table 3 show the distribution of students by indicators of awareness about SGBV at baseline and endline. There was a significant increase in the proportion of students reporting that girls are teased or sexually harassed verbally at school from $24 \%$ at baseline to $38 \%$ at endline $(p<0.01)$. By contrast, there was a significant decrease in the proportion of students that reported having heard of a schoolboy who was forced to have sex with a teacher from $6 \%$ at baseline to $1 \%$ at endline $(p<0.05)$. 
Table 3: Distribution of students by awareness about sexual and gender-based violence at school and in the community

\begin{tabular}{|l|l|l|}
\hline Indicators of awareness & $\begin{array}{l}\text { Baseline (\%) } \\
\mathbf{( N = 2 4 7 )}\end{array}$ & $\begin{array}{l}\text { Endline (\%) } \\
\mathbf{( N = 1 4 3 )}\end{array}$ \\
\hline Feels unsafe or fearful at school & 14.2 & 14.7 \\
\hline Feels unsafe/fearful walking to or from school & 17.4 & 12.6 \\
\hline Fighting or violence exists in school & 19.8 & 22.4 \\
\hline Theft or stealing exists in school & 46.6 & $57.3^{\star}$ \\
\hline Girls forced to do things for better grades & 8.1 & 7.0 \\
\hline Girls teased or sexually harassed verbally at school & 24.3 & $37.8^{* *}$ \\
\hline Sexual abuse very or somewhat common at school & 37.7 & 35.0 \\
\hline Heard of school girl forced to have sex with teacher & 15.4 & 16.8 \\
\hline Heard of school boy forced to have sex with teacher & 5.7 & $1.4^{*}$ \\
\hline Heard of school girl forced to have sex with another student & 8.9 & 12.6 \\
\hline Heard of school boy forced to have sex with another student & 1.6 & 2.8 \\
\hline Sexual abuse against girls very or somewhat common in the community & 58.7 & 65.7 \\
\hline
\end{tabular}

Notes: $\quad{ }^{*} \mathrm{p}<0.05 ;{ }^{* *} \mathrm{p}<0.01$.

The most common forms of sexual violence against girls in the school setting that were reported by students were touching of private parts (29\% at baseline and $26 \%$ at endline), making sexual comments or teasing about sex (7\% at baseline and $22 \%$ at endline), and people exposing their bodies (6\% at baseline and $7 \%$ at endline; Figure 1). There was a significant increase between baseline and endline in the proportion of girls reporting sexual comments or teasing about sex as a form of sexual violence against girls in the school setting $(p<0.01)$ (Table 3). Similarly, there was a significant decrease in the proportion of girls that reported that there was no sexual violence against girls in the school (from $42 \%$ at baseline to $15 \%$ at endline; $p<0.01$ ) (Figure 1).

Figure 1: Distribution of students by reported forms of sexual violence against girls at school at baseline and endline

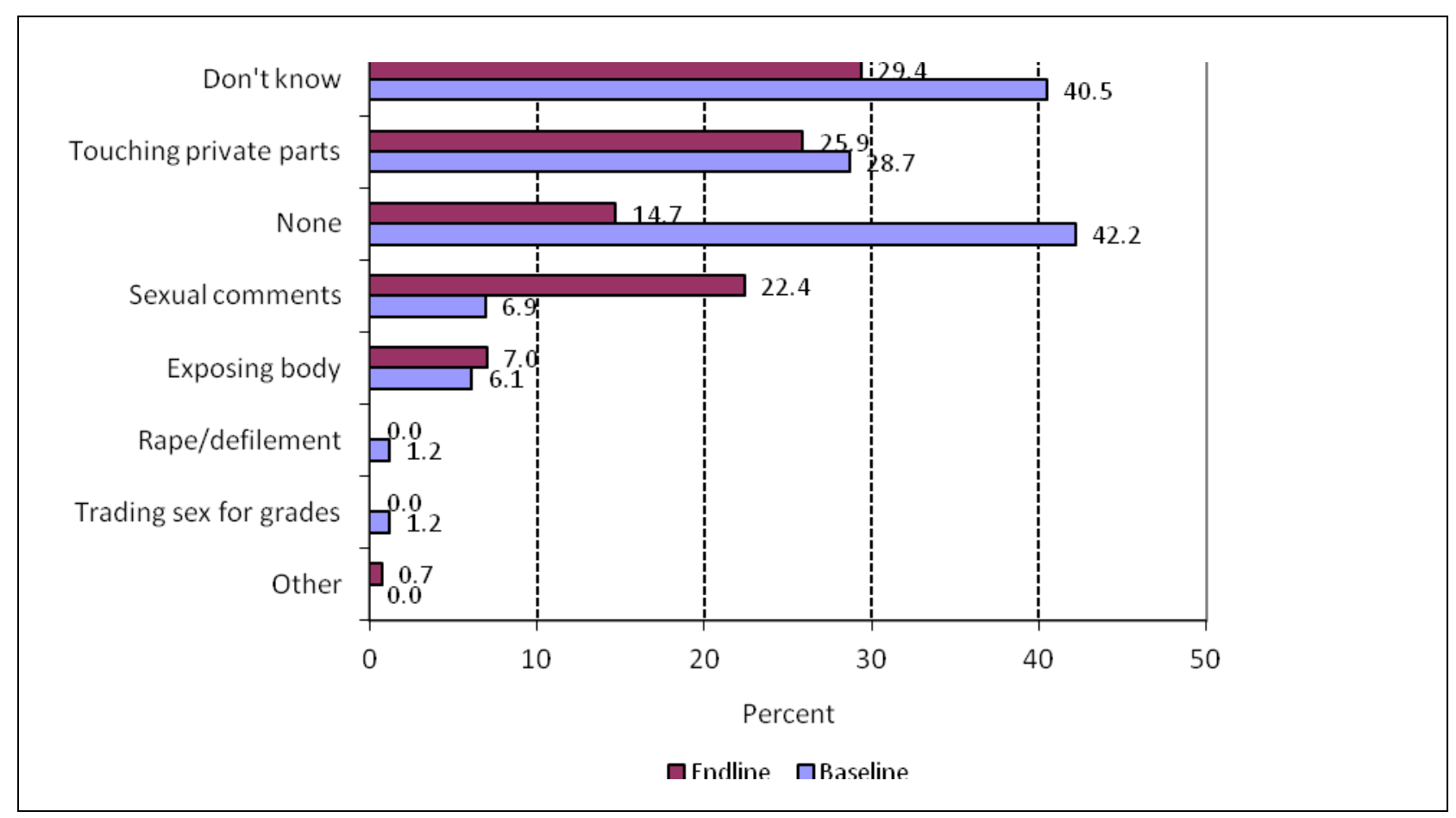


The most common forms of sexual violence against girls in community settings that were reported by students were making sexual comments or teasing about sex $(11 \%$ at baseline and $13 \%$ at endline), touching of private parts ( $7 \%$ at baseline and a similar proportion at endline), and people exposing their bodies ( $4 \%$ at baseline and $6 \%$ at endline; Figure 2 ).

Figure 2: Distribution of students by reported forms of sexual violence against girls in the community at baseline and endline

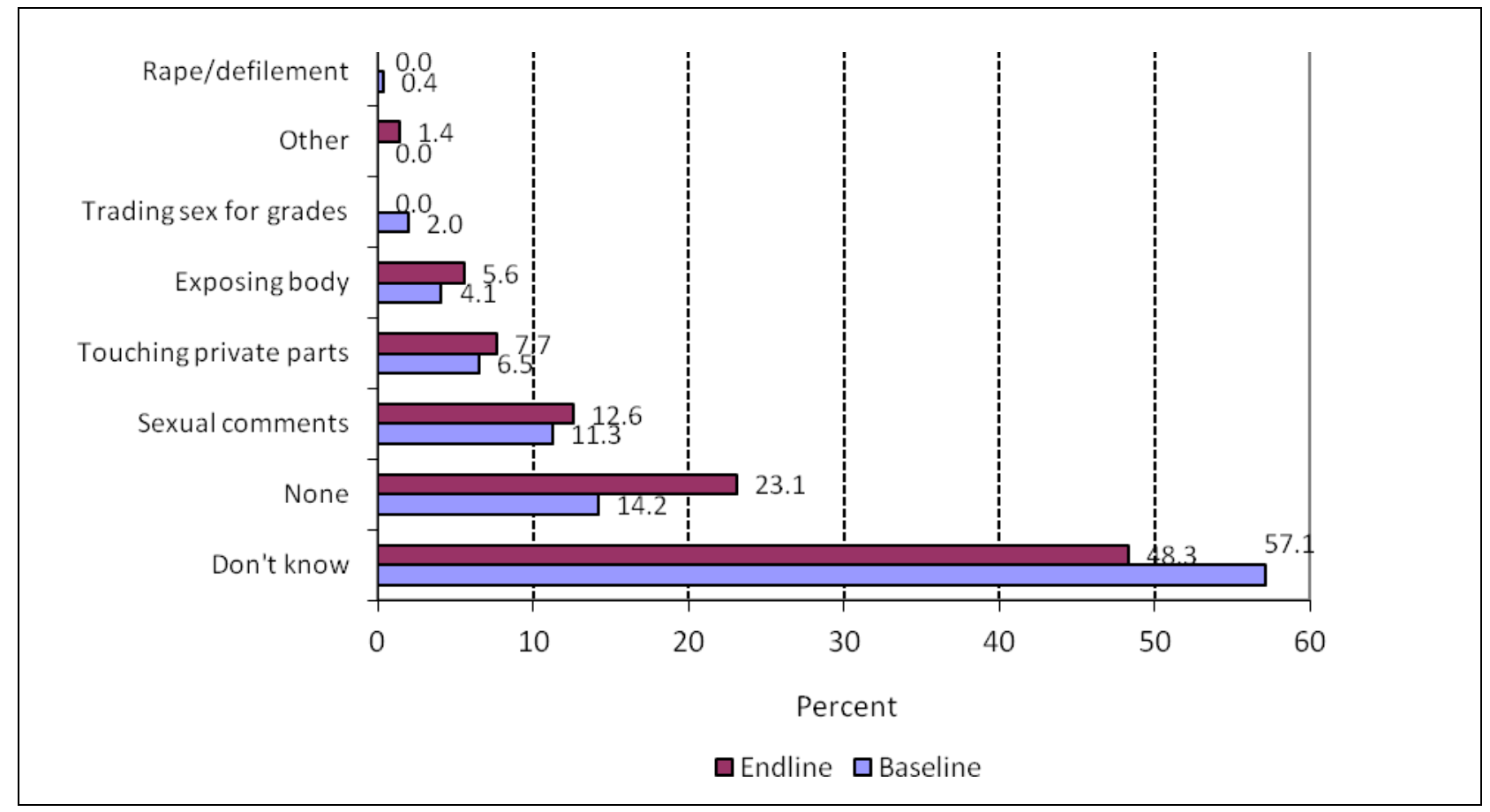

The 'Don't know' categories in Figures 1 and 2 referred to the fact that respondents were not aware of whether any forms of sexual violence against girls occurred at school or in the community, while the 'None' categories indicate these kinds of violence did not occur at school or in the community. The reduction in both categories between baseline and endline suggests that awareness of forms of sexual violence against girls occurring at the school level increased over time.

\section{Practices and Experiences Related to Sexual and Gender-based Violence}

Table 4 presents the distribution of students by practices related to sexual and gender-based violence at baseline and endline. Although there was a decline in the proportion of students reporting that that they ever made sexual comments to school mates at their current institutions (from $14 \%$ at baseline to $8 \%$ at endline), the change was not statistically significant $(p=0.07)$. There was, however, a significant increase in the proportion of students that indicated that they would report incidents of sexual comments by another student to teachers, the school principal or the police (from $41 \%$ at baseline to $57 \%$ at endline; $p<0.01$ ). Nonetheless, there was no significant change in the proportion of students that indicated that they would report requests by a teacher to have sex to other teachers, the school principal or the police (38\% at baseline and $40 \%$ at endline; $\mathrm{p}=0.67$ ). In addition, there was no significant change in the proportions of students that reported that they would decline sexual advances from a student (69\% at baseline and a similar proportion at endline) or from a teacher ( $47 \%$ at baseline and $43 \%$ at endline). 
Table 4: Distribution of students by sexual and gender-based violence practices

\begin{tabular}{|l|l|l|}
\hline Indicators & $\begin{array}{l}\text { Baseline (\%) } \\
(\mathrm{N}=\mathbf{2 4 7})\end{array}$ & $\begin{array}{l}\text { Endline (\%) } \\
(\mathrm{N}=143)\end{array}$ \\
\hline $\begin{array}{l}\text { Ever made sexual comments to a school mate at current } \\
\text { school }\end{array}$ & 13.8 & 7.7 \\
\hline $\begin{array}{l}\text { Would report incidents of sexual comments by another } \\
\text { student to teachers/ principal/ police }\end{array}$ & 40.5 & $57.3^{* *}$ \\
\hline $\begin{array}{l}\text { Would say no/not agree to requests by another student to } \\
\text { have sex }\end{array}$ & 68.8 & 68.5 \\
\hline $\begin{array}{l}\text { Would report requests by another student to have sex to } \\
\text { teachers/ principal/ police }\end{array}$ & 17.8 & 21.0 \\
\hline $\begin{array}{l}\text { Would say no/not agree to requests by a teacher to have } \\
\text { sex }\end{array}$ & 47.4 & 42.7 \\
\hline $\begin{array}{l}\text { Would report requests by a teacher to have sex to other } \\
\text { teachers/ principal/ police }\end{array}$ & 37.7 & 39.9 \\
\hline
\end{tabular}

Notes: ${ }^{*} p<0.05 ; * \mathrm{*}<0.01$.

With respect to experiences of sexual and gender-based violence, there was a significant increase in the proportion of students that reported that their colleagues at the current school made sexual comments to them when they did not want them to (from 19\% at baseline to $34 \%$ at endline; $p<0.01$; Table 5). Similarly, there was a significant increase in the proportion of students that reported having been physically abused in the community (from $24 \%$ at baseline to $40 \%$ at endline $(p<0.01)$. There was also a significant increase in the proportion of students that reported ever experiencing at least one of the forms of sexual and gender-based violence considered (from $50 \%$ at baseline to $67 \%$ at endline; $p<0.01$; Table 5 ). By contrast, the proportion of students that reported that they did not experience any form of sexual and gender-based violence remained unchanged (30\% at both baseline and endline).

Table 5: Distribution of students by experiences of sexual and gender-based violence at school and in the community

\begin{tabular}{|l|l|l|}
\hline Indicator & $\begin{array}{l}\text { Baseline (\%) } \\
(\mathbf{N}=\mathbf{2 4 7})\end{array}$ & $\begin{array}{l}\text { Endline (\%) } \\
(\mathbf{N}=\mathbf{1 4 3})\end{array}$ \\
\hline School mates at current school ever made sexual comments & 19.4 & $34.3^{* *}$ \\
\hline School mates at current school ever forced respondent to have sex & 2.8 & 3.5 \\
\hline Teachers at current school ever made sexual comments to respondent & 6.1 & 3.1 \\
\hline Teachers at current school ever forced respondent to have sex & 0.8 & 0.0 \\
\hline Ever been physically abused in the community & 24.3 & $39.9^{* *}$ \\
\hline Ever been sexually abused in the community & 20.2 & 21.0 \\
\hline Ever been forced to have sex in the community & 9.1 & 10.5 \\
\hline Ever been physically abused by boyfriend/non-steady partner & 6.9 & 7.0 \\
\hline Ever been coerced/persuaded to have sex by boyfriend/non-steady partner & 13.4 & 16.1 \\
\hline Ever been forced to have sex by boyfriend/non-steady partner & 9.7 & 10.5 \\
\hline Ever experienced any of the above forms of violence & 50.2 & $67.1^{* *}$ \\
\hline Did not experience any of the above forms of violence & 30.0 & 30.0 \\
\hline
\end{tabular}

Notes: $\quad * p<0.05 ;{ }^{* *} p<0.01$.

The most common perpetrators of physical abuse in the community that were mentioned by students at both baseline and endline were strangers (39\%), other persons (13\%), male neighbours $(11 \%)$, male siblings (10\%), uncles (9\%), and fathers (8\%); Figure 3). Similarly, the most common perpetrators of sexual abuse in the community that were mentioned by students at both baseline and endline were strangers (21\%), male neighbours (16\%), male friends (15\%), boy/girlfriends $(13 \%)$, other persons (8\%), and uncles (6\%; Figure 3). The 'Other' category in Figure 3 includes the following persons: herd boys, garden boys, pastors, cousins, people in authority in the community, and spouses. 
Figure 3: Distribution of students by reported perpetrators of sexual and gender-based violence in the community for combined baseline and endline

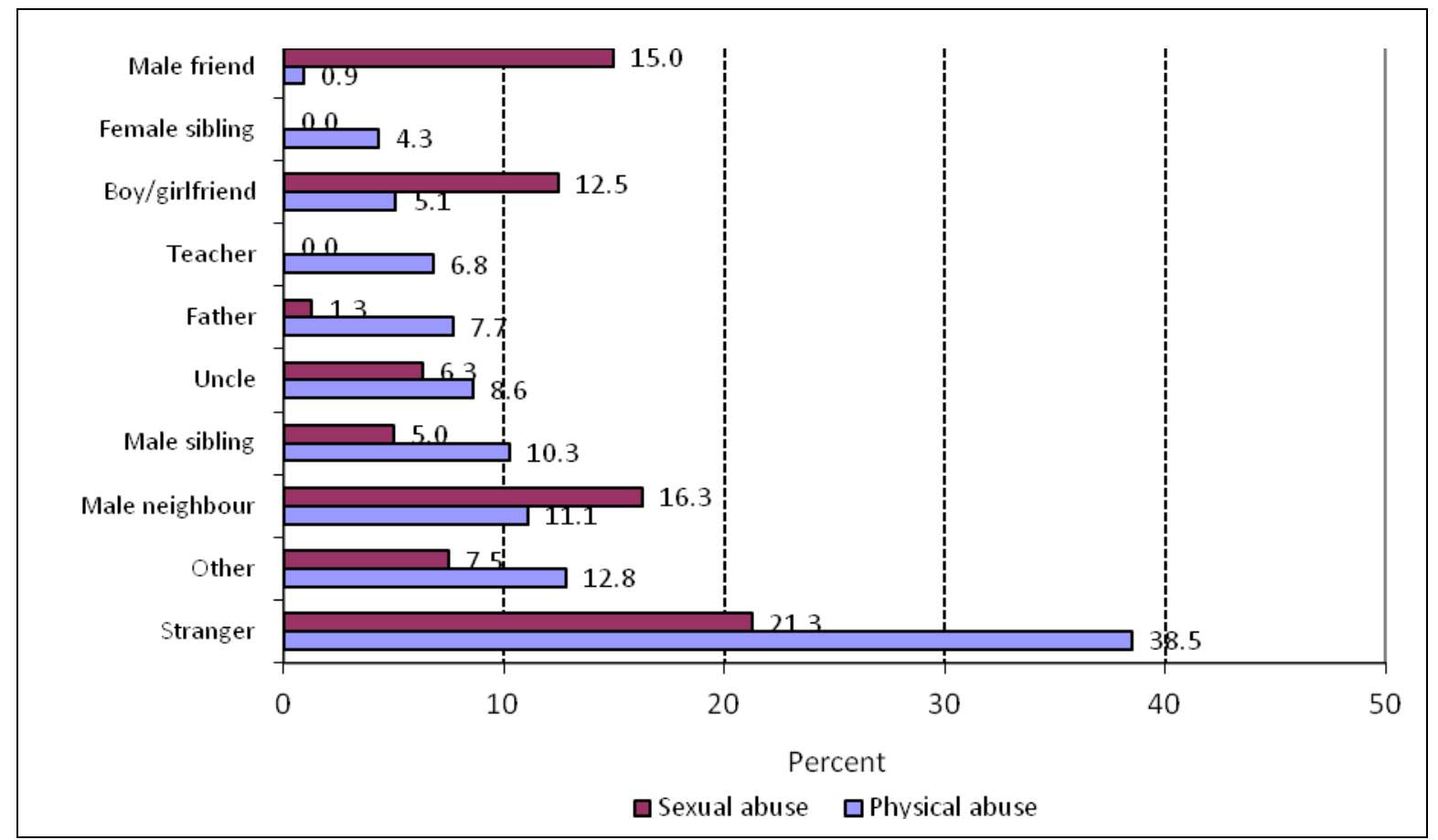

\section{Attitudes towards Sexual and Gender-based Violence}

At both baseline and endline, students were asked whether they agreed or disagreed with a series of statements on sexual and gender-based violence. The results are presented in Table 6 . There was a significant increase between baseline and endline in the proportion of students that disagreed with the statements that: (i) it is more important for boys to get education than girls (from $87 \%$ to $95 \%$; $\mathrm{p}<0.05$ ); (ii) it is the man who decides when to have sex (from $58 \%$ to $71 \%$; $p<0.05$ ); (iii) it is a woman's or girl's responsibility to avoid being raped (from 34\% to 45\%; $p<0.05$ ); (iv) male students have a right to demand sex from school girls (from 92\% to 97\%; $p<0.05$ ); (v) any male relative has the right to demand sex from a girl or woman (from 90\% to 98\%; $p<0.01$ ); (vi) it is often a girl's fault if she is raped (from $81 \%$ to $89 \%$; $p<0.05$ ); (vii) it is often a woman's fault if she is raped (from $81 \%$ to $91 \%$; $p<0.01$ ); (viii) only bad girls are teased sexually by boys (from $66 \%$ to $87 \%$; $p<0.01$ ); (ix) only bad girls are teased sexually by teachers (from 69\% to 88\%; $p<0.01$ ); ( $x$ ) a woman or girl who has been raped brings shame to the family (from 76\% to $90 \%$; $p<0.01$ ); (xi) it is okay for a man to have sex with his wife even when she does not want to (from $73 \%$ to $90 \% ; p<0.01$ ), and (xii) women often lie about rape or defilement to punish men (from $36 \%$ to $55 \%$; $p<0.01$ ).

Results in Table 6 further show that there was a significant increase between baseline and endline in the proportion of students that agreed with the statements that: (i) a teenage girl who gets pregnant should be allowed to stay in school (from 34\% and 50\%; $p<0.01$ ); (ii) women and girls have a right to refuse sex (from $81 \%$ and $91 \%$; $p<0.01$ ); and (iii) men and boys can do something to prevent sexual violence against women and girls (from $67 \%$ and $83 \%$; $p<0.01$ ). 
Table 6: Distribution of students by attitudes towards sexual and gender-based violence

\begin{tabular}{|c|c|c|}
\hline Indicator & $\begin{array}{l}\text { Baseline (\%) } \\
(\mathrm{N}=247)\end{array}$ & $\begin{array}{l}\text { Endline (\%) } \\
(\mathrm{N}=143)\end{array}$ \\
\hline $\begin{array}{l}\text { Women should have same rights as men } \\
\text { Agree } \\
\text { Disagree }\end{array}$ & $\begin{array}{l}71.7 \\
18.2\end{array}$ & $\begin{array}{l}75.5^{* *} \\
20.3\end{array}$ \\
\hline $\begin{array}{l}\text { Pregnant teenage girl should be allowed to stay in school } \\
\text { Agree } \\
\text { Disagree }\end{array}$ & $\begin{array}{l}34.0 \\
54.7\end{array}$ & $\begin{array}{l}50.4 * * \\
43.4 *\end{array}$ \\
\hline $\begin{array}{l}\text { It is more important for boys to get education than girls } \\
\text { Agree } \\
\text { Disagree }\end{array}$ & $\begin{array}{l}4.9 \\
87.0 \\
\end{array}$ & $\begin{array}{l}2.8 \\
95.1 *\end{array}$ \\
\hline $\begin{array}{l}\text { Girls in the community have same opportunities for education as boys } \\
\text { Agree } \\
\text { Disagree }\end{array}$ & $\begin{array}{l}72.9 \\
9.7\end{array}$ & $\begin{array}{l}73.4 \\
8.4\end{array}$ \\
\hline $\begin{array}{l}\text { It is the man who decides when to have sex } \\
\text { Agree } \\
\text { Disagree }\end{array}$ & $\begin{array}{l}9.7 \\
57.9\end{array}$ & $\begin{array}{l}7.7 \\
70.6 *\end{array}$ \\
\hline $\begin{array}{l}\text { Women and girls have a right to refuse sex } \\
\text { Agree } \\
\text { Disagree }\end{array}$ & $\begin{array}{l}80.6 \\
6.5\end{array}$ & $\begin{array}{l}90.9 * * \\
7.7\end{array}$ \\
\hline $\begin{array}{l}\text { It is a woman's or girl's responsibility to avoid being raped } \\
\text { Agree } \\
\text { Disagree }\end{array}$ & $\begin{array}{l}38.5 \\
34.4\end{array}$ & $\begin{array}{l}42.7 \\
44.8 *\end{array}$ \\
\hline $\begin{array}{l}\text { Male teachers have a right to demand sex from school girls } \\
\text { Agree } \\
\text { Disagree }\end{array}$ & $\begin{array}{l}2.8 \\
89.1\end{array}$ & $\begin{array}{l}2.8 \\
94.4\end{array}$ \\
\hline $\begin{array}{l}\text { Male pupils have a right to demand sex from school girls } \\
\text { Agree } \\
\text { Disagree }\end{array}$ & $\begin{array}{l}0.8 \\
91.5\end{array}$ & $\begin{array}{l}1.4 \\
97.2 *\end{array}$ \\
\hline $\begin{array}{l}\text { Any male relative has a right to demand sex from a girl or woman } \\
\text { Agree } \\
\text { Disagree }\end{array}$ & $\begin{array}{l}0.4 \\
90.3\end{array}$ & $\begin{array}{l}0.0 \\
97.9 * *\end{array}$ \\
\hline $\begin{array}{l}\text { Sexual violence should be kept secret } \\
\text { Agree } \\
\text { Disagree }\end{array}$ & $\begin{array}{l}5.3 \\
83.4\end{array}$ & $\begin{array}{l}1.4 \\
97.2 * *\end{array}$ \\
\hline $\begin{array}{l}\text { It is often a girl's fault if she is raped } \\
\text { Agree } \\
\text { Disagree }\end{array}$ & $\begin{array}{l}7.7 \\
81.0\end{array}$ & $\begin{array}{l}7.0 \\
88.8 *\end{array}$ \\
\hline $\begin{array}{l}\text { It is often a woman's fault if she is raped } \\
\text { Agree } \\
\text { Disagree }\end{array}$ & $\begin{array}{l}5.7 \\
81.0\end{array}$ & $\begin{array}{l}7.0 \\
90.9 * *\end{array}$ \\
\hline $\begin{array}{l}\text { Only bad girls are teased sexually by boys } \\
\text { Agree } \\
\text { Disagree }\end{array}$ & $\begin{array}{l}11.3 \\
66.4\end{array}$ & $\begin{array}{l}9.8 \\
86.7 * *\end{array}$ \\
\hline $\begin{array}{l}\text { Only bad girls are teased sexually by teachers } \\
\text { Agree } \\
\text { Disagree }\end{array}$ & $\begin{array}{l}8.1 \\
69.2\end{array}$ & $\begin{array}{l}7.7 \\
88.1 * *\end{array}$ \\
\hline $\begin{array}{l}\text { Men and boys can do things to prevent sexual violence against women and girls } \\
\text { Agree } \\
\text { Disagree }\end{array}$ & $\begin{array}{l}66.8 \\
9.3\end{array}$ & $\begin{array}{l}82.5^{* *} \\
9.1\end{array}$ \\
\hline $\begin{array}{l}\text { I can say no to a teacher who wants to have sex with me } \\
\text { Agree } \\
\text { Disagree }\end{array}$ & $\begin{array}{l}88.3 \\
3.6 \\
\end{array}$ & $\begin{array}{l}93.7 \\
4.2 \\
\end{array}$ \\
\hline $\begin{array}{l}\text { I can say no to a student who wants to have sex with me } \\
\text { Agree } \\
\text { Disagree }\end{array}$ & $\begin{array}{l}87.0 \\
6.1\end{array}$ & $\begin{array}{l}90.2 \\
6.3\end{array}$ \\
\hline $\begin{array}{l}\text { A woman or girl who has been raped brings shame to family } \\
\text { Agree } \\
\text { Disagree }\end{array}$ & $\begin{array}{l}7.3 \\
75.7\end{array}$ & $\begin{array}{l}6.3 \\
90.2 * *\end{array}$ \\
\hline $\begin{array}{l}\text { It is okay for man to have sex with his wife even when she does not want } \\
\text { Agree } \\
\text { Disagree }\end{array}$ & $\begin{array}{l}6.5 \\
72.5 \\
\end{array}$ & $\begin{array}{l}2.8 \\
90.2 * *\end{array}$ \\
\hline $\begin{array}{l}\text { Women often lie about rape or defilement to punish men } \\
\text { Agree } \\
\text { Disagree }\end{array}$ & $\begin{array}{l}19.0 \\
36.0\end{array}$ & $\begin{array}{l}27.3 \\
55.2 * *\end{array}$ \\
\hline
\end{tabular}

Notes: $\quad{ }^{*} p<0.05 ;{ }^{* *} p<0.01$. 
The Girls' Empowerment Clubs Plus project in Swaziland used an SGBV-focused 'Safe Spaces' approach to enhance SGBV knowledge, attitudes, and practices among in-school girls, with an ultimate goal of preventing SGBV and improving the reporting of the same. This evaluation of the GEC-Plus project yields key findings that demonstrate the ability of the GEC-Plus model to contribute to improved SGBV outcomes, and to the potential for the model to be scaled up in partnership with the Ministry of Education.

The major findings of the evaluation are summarized below:

- There were significant improvements in girls' social assets as a result of the interventions: There were significant increases between baseline and endline in the proportions of girls that reported that they were engaged in an income-generating activity (from $6 \%$ to $13 \%$ ), had many friends in the neighbourhood (from $41 \%$ to $52 \%$ ), had two or more close friends they could confide in (from 60\% to 74\%), or that they were taking part in extra curricula activities (from 68\% to $100 \%)$.

- There were significant improvements in awareness about sexual and gender-based violence among girls as a result of the interventions: The proportion of students who reported that girls in their institutions were teased or subjected to verbal sexual harassment significantly increased from $24 \%$ at baseline to $38 \%$ at endline. In addition, the proportion of girls that reported being subjected to sexual comments by fellow students at their current institutions significantly increased from 19\% at baseline to $34 \%$ at endline. Similarly, the proportion of students that reported being physically abused in the community significantly increased from $24 \%$ at baseline to $40 \%$ at endline. The proportion of students that reported ever experiencing any form of sexual and gender-based violence either at school or in the community also significantly increased from $50 \%$ at baseline to $67 \%$ at endline. There was also a significant increase in the proportion of girls that reported prevalence of theft or stealing in their schools from $47 \%$ at baseline to $57 \%$ at endline.

- There were some improvements in the likelihood that girls would report incidents of sexual harassment: The proportion of girls that indicated that they would report incidents of sexual comments by another student to teachers, the school principal, or the police significantly increased from $41 \%$ at baseline to $57 \%$ at endline. Nonetheless, there was no significant change in the proportion of students that indicated that they would report sexual comments by a teacher to fellow teachers, the school principal, or the police (from 38\% at baseline to $40 \%$ at endline).

- The interventions did not have any effect on the likelihood that girls would decline sexual advances from students or teachers: There was no significant change between baseline and endline in the proportion of students that reported that they would decline sexual advances from a student (69\% at baseline and a similar proportion at endline) or from a teacher $(47 \%$ at baseline and $43 \%$ at endline).

- There were significant positive changes in the attitudes of students regarding sexual and gender-based violence: Students reported significant positive changes in 13 out of a total of 21 items used to measure attitudes towards SGBV. The changes were characterized by significant increases between baseline and endline in the proportions of students that disagreed with statements that justified sexual and gender-based violence as well as significant increases in the proportions that agreed with statements that promoted the rights of women and girls in society. 


\section{CONCLUSION AND RECOMMENDATIONS}

The findings of the study show very high levels of reported abuse among in-school girls in Swaziland. The GEC-Plus interventions were effective in improving girls' social assets, increasing their awareness, and positively changing their attitudes towards SGBV. The interventions were, however, less successful in changing the possibility that the students would decline sexual advances from fellow students or teachers.

The fact that the interventions did not have any effect on changing the possibility that students would decline sexual advances from either a teacher or student suggests that the interventions could further be strengthened by incorporating components aimed at enhancing self-efficacy among girls. As the most common perpetrators of some kinds of abuse experienced by in-school girls were found in the wider community (strangers, other persons, male neighbours, male siblings, uncles, and fathers), integrating the GEC-Plus program within the wider community would be important. This could help establish a more holistic program, and would make for a more sustainable project. Stronger community ties would promote positive publicity for the project and increase its reach to more girls and other populations (out of school girls for example, or boys and men whom girls in this study report as often being perpetrators).

The program could also be improved through diversification of the activities for the girls, while maintaining a key focus on SGBV. This diversification would open up a new world to the girls by pushing them into different domains: sport, arts, economic activities, community improvements, etc. Following this idea, more presentations by guest speakers on different topics (career, education, etc.) could also help the girls develop their dreams. These new activities or presentations would help the program to scale its operations up as well as publicize its mission, which is currently an issue.

A critical element to sustainability is ownership and institutionalisation. To this end, SWAGAA and key stakeholders need to engage in extensive advocacy and lobbying to facilitate adoption of the GEC-Plus program by the Government of Swaziland through the Ministry of Education. This would not only improve the coverage in terms of reach but also ensure mainstreaming into the school curricula, thus securing commitment from schools administrators and teachers. 


\section{REFERENCES}

Austrian, K. and D. Ghati. 2010. Girl Centered Program Design: A Toolkit to Develop, Strengthen and Expand Adolescent Girls Programs. New York: Population Council.

Babbie, E. 2011. The Basics of Social Research (5th Edition). Wadsworth, USA: CENGAGE Learning.

Baldwin, W. 2011. Creating 'Safe Spaces' for Adolescent Girls. Promoting Healthy, Safe, and Productive Transitions to Adulthood. Brief No. 39.

http://www.popcouncil.org/pdfs/TABriefs/39_SafeSpaces.pdf.

Brady, M., A. Ragui, I. Barbara, S. Abeer, S. Rania, and N. Zibani. 2007. Providing New Opportunities to Adolescent Girls in Socially Conservative Settings: The Ishraq Program in Rural Upper Egypt. New York: Population Council.

Catino, J., Ruiz, M.J., Hallman, K. Roca, E., Weiner,A., Colom, A., and Contreras-Aprile, S. 2009. For Mayan girls, leadership skills and participation in a national network lead to social, economic, and political gains. Promoting Healthy, Safe, and Productive Transitions to Adulthood Brief, No. 5.

Central Statistical Office (CSO) [Swaziland] and Macro International Inc. 2008. Swaziland Demographic and Health Survey 2006-07. Mbabane, Swaziland: Central Statistical Office and Macro International Inc.

Erulkar, A.S., Mekbib, T.A., and Tegegne, M. 2008. BiruhTesfa: Creating a 'Bright Future' for migrant girls in urban areas of Ethiopia. Promoting Healthy, Safe, and Productive Transitions to Adulthood Brief, No. 21.

Erulkar, A.S and Ferede, A. 2009. "Social exclusion and early or unwanted sexual initiation among poor urban females in Ethiopia." International Perspectives on Sexual and Reproductive Health 35(4): 186-193.

Jewkes R., Dunkle, K,, Nduna, M., and Shai, N., 2010. Intimate partner violence, relationship power inequity, and incidence of HIV infection in young women in South Africa: a cohort study. The Lancet 376 (9734): 41-48.

Mitchell, M.L. and Jolly, J.M. 2010. Research Design Explained. Wadsworth, USA: CENGAGE Learning.

National Gender Policy [Swaziland]. 2010. Government Press Statement August 24, 2010.

Reza, A., Breiding, M, Blanton, C., Mercy, J.A., Dahlberg, L..L., Anderson, M., and Bamrah. S. 2007. Violence against children in Swaziland: Findings from a national survey on violence against children in Swaziland. Mbabane: Centre for Disease Control and Prevention and United Nation's Children's Fund.

Reza, A., Breiding, M., Gulaid, J. et al., 2009. "Sexual violence and its health consequences for female children in Swaziland: a cluster survey study." Lancet 373(9679): 1966-1972.

SWAGAA. 2011. Swaziland Action Group Against Abuse Annual Report 2010-2011. 